Original Article

\title{
ASSESSMENT OF PHYTOCHEMICALS AND IN VITRO ANTIOXIDANT, ANTI-INFLAMMATORY ACTIVITY OF SARCOSTEMMA BRUNONIANUM WIGHT AND ARN
}

\author{
AMALA DIVYA S. ${ }^{*}$, THAMARAIKANI V.1, SEKAR T. ${ }^{2}$ \\ 1,2Department of Botany, Bharathiar University, Coimbatore, Tamil Nadu 641046 \\ Email: amaladivyas171093@gmail.com
}

Received: 15 Sep 2020, Revised and Accepted: 17 Nov 2020

\begin{abstract}
Objective: Sarcostemma brunonianum Wight and Arn is a potential medicinal plant belonging to Asclepiadaceae. Bioactive constituents of the plant support the application of treating various ailments in the traditional system of medicine. The study aims to determine the presence of various phytoconstituents in stem, root, and flowers.

Methods: Hot percolation method was carried out to obtain crude extracts using different solvent systems from low polar-high polar solvents ranging from petroleum ether, chloroform, (mid-polar) ethyl acetate, methanol and water. Estimation of total phenols, tannins and In vitro antioxidant, anti-inflammatory activities were evaluated for the determination of potential pharmaceutical drugs.

Results: The results revealed the presence of some phytoconstituents such as phenols, tannins, glycosides, gums and mucilages. Ascorbic acid, BSA, Rutin and Gallic acid were used as the reference standard. The total phenolic content was found to be high in stem methanol extract $440.84 \pm 69.99$ $\mathrm{mg} / \mathrm{g}$ Gallic acid equivalent, whereas the tannin content was $291.78 \pm 4.68 \mathrm{mg} / \mathrm{g}$ GAE. The result proves that the $S$. brunonianum stem methanol extract possesses antioxidant and anti-inflammatory activities when compared to reference standards. In vitro, Nitric oxide scavenging activity of stem showed a maximum \% of inhibition in methanol stem extract $(24.39 \mu \mathrm{g} / \mathrm{ml})$ and anti-inflammatory activity maximum inhibition was found to be (55.56 \%) in stem methanol and flower(53.62 \%). The IC50 (concentration required for 50\% inhibition) was also calculated for the DPPH radical model.
\end{abstract}

Conclusion: This study results proclaims and justifies the role of folklore medicinal plant S. brunonianum in the treatment of inflammatory-related ailments and can be recommended for an effective drug.

Keywords: Sarcostemma brunonianum, Phytochemicals, Antioxidants, Anti-inflammatory

(C) 2021 The Authors. Published by Innovare Academic Sciences Pvt Ltd. This is an open access article under the CC BY license (https://creativecommons.org/licenses/by/4.0/) DOI: https://dx.doi.org/10.22159/ijcpr.2021v13i1.40819. Journal homepage: https://innovareacademics.in/journals/index.php/ijcpr

\section{INTRODUCTION}

S. brunonianum a latex bearing climber commonly used as an emetic by local people of Eastern Ghats of Tamil Nadu [1]. The rural people of Maruthamalai hills, Coimbatore are using the plant stem is used as a medicine for snake bites, dyspepsia and various illness. Commonly, it is called Perumaattaan Kodi [2]. The plant has been traditionally used in different areas of India especially the roots are used in treating snakebite and taken as an infusion in dog bite cases [3] Sarcostemma existing in warmer regions of the world like India, China, Pakistan, Srilanka, The perennial, fleshy, glabrous branched, milky latex secreting shrub posses various religious and pharmacological significances [4]. Several species of Sarcostemma genera resemble each other on similar morphological characters. The plant $S$. acidum is well used by the tribal people for asthma, swelling, fever, colds, dyspepsia, inflammatory infection and gastric problem [5]. The fresh plant material of $S$. viminale is minced and mixed with margarine, then applied to wounded areas [6]. The composite mixture of bioactive materials synthesized by plants is responsible for metabolic functions, recently, these plant metabolites are referred to as phytochemicals [7].

The explorations of medicinal plants are considered as a relevant source in the production of new drugs is getting increased day by day. The demand for plant resources leads to research on bioprospecting fields. Free radicals and reactive oxygen species are the main cause of the troubling of physiological as well as metabolic activities [8]. Free radicals are any chemical species that are capable of existing with one or more unpaired electrons and are extremely reactive and highly unstable [9]; non-natural phenolic antioxidants such as $(B H T)$ butylated hydroxytoluene, $(B H A)$ Butylated hydroxyl anisole antioxidants were widely used as a food preservative and its consumption leads to affect various organs like kidney, liver, and skin on moderate to excessive level [10]. Many plants frequently contain substantial amounts of antioxidants, including vitamins, carotenoids, flavonoids, phenols, and tannins, etc. and thus can be utilized to scavenge the unpaired electrons [11]. Various researchers are still in active practice to develop new drugs with efficient antioxidant activity.

In such a way, the study focused to utilize least utilized laticifer Sarcostemma brunonianum Wight and Arn to explore the photo components, to check antioxidant capacity and anti-inflammatory properties.

\section{MATERIALS AND METHODS}

\section{Collection and processing of the plant materials}

The fresh stem, root, and flowers of S. brunonianum were collected from the Maruthamalai forest of Western Ghats, Coimbatore District, Tamil Nadu state. The collected plant materials were identified, and they are authenticated by the Botanical Survey of India, Southern Regional Centre, Coimbatore. The collected plant materials were cleaned and shade dried, powdered and stored for further studies.

\section{Successive solvent extraction of plant parts}

The powdered plant material was extracted in the Soxhlet apparatus successively with petroleum ether, chloroform, ethyl acetate, methanol, and water. The different solvent extracts obtained were concentrated and then air-dried.

\section{Qualitative phytochemical screening}

The stem, root, and flower extracts of $S$. brunonianum were tested for the presence of major phytochemicals such as alkaloids, saponins, phenolic compounds, tannins, flavonoids, glycosides, phytosterols, fixed oils and fats, and gums and mucilages according to standard methods [12-15]. 


\section{Phenolic compounds}

\section{Ferric chloride test}

About $50 \mathrm{mg}$ of the plant sample was dissolved in $5 \mathrm{ml}$ of distilled water. To this, a few drops of $5 \%$ neutral ferric chloride solution was added. Phenolic compounds were indicated by the presence of a dark green color.

\section{Tannins}

\section{Potassium hydroxide test}

The plant material $(0.5 \mathrm{~g})$ was added into $10 \mathrm{ml}$ of freshly prepared $10 \%$ potassium hydroxide $(\mathrm{KOH})$ in a beaker and shaken to dissolve. A dirty precipitate indicates the occurrence of tannin.

\section{Glycosides}

\section{Borntrager's test}

$50 \mathrm{mg}$ of plant material was hydrolyzed with concentrated hydrochloric acid for two hrs on a water bath and filtered. About 2 $\mathrm{ml}$ of filtrate is added with $3 \mathrm{ml}$ of chloroform and shaken. The chloroform layer was separated and a $10 \%$ ammonia solution was added to it. The pink color indicated the presence of glycosides.

\section{Fixed oils and fats}

\section{Saponification test}

A few drops of $0.5 \mathrm{~N}$ alcoholic potassium hydroxide solutions were added to some samples along with a drop of phenolphthalein. The mixture was kept under a boiling water bath for $2 \mathrm{~h}$. The formation of soap indicates the occurrence of fixed oils and fats.

\section{Gums and mucilage}

\section{Absolute alcohol test}

About $100 \mathrm{mg}$ of plant sample was dissolved in $10 \mathrm{ml}$ of distilled water followed by $25 \mathrm{ml}$ of absolute alcohol was added with continuous stirring. White precipitate indicates the existence of gums and mucilage.

\section{Quantification of total phenolic and tannin contents}

The total phenolic content was determined according to the method described by [16]. Fifty $\mathrm{ml}$ triplicates of the extracts $(20 \mathrm{mg} / 20 \mathrm{ml})$ were taken in the test tubes and makeup to the volume of $1 \mathrm{ml}$ with distilled water. About $0.5 \mathrm{ml}$ of Folin and Ciocalteu phenol reagent (1:1 with water) and $2.5 \mathrm{ml}$ sodium carbonate solution (20\%) were added successively in each tube. The reaction mixtures were vortexed and all the test tubes were kept under dark incubation for $40 \mathrm{~min}$ and the absorbance was recorded at $725 \mathrm{~nm}$ against the reagent blank. The investigation was done in triplicate and the results were expressed in gallic acid equivalents.

The tannin contents were estimated using the same extract after treatment with polyvinyl polypyrrolidine (PVPP) [17], $100 \mathrm{mg}$ of PVPP was weighed into transferred into Eppendorf tube. About 1 $\mathrm{ml}$ of distilled water was added along with $1 \mathrm{ml}$ of the sample extracts. The whole content was vortexed and kept in the freezer at $4{ }^{\circ} \mathrm{C}$ for $15 \mathrm{~min}$. Next, the samples were centrifuged for $10 \mathrm{~min}$ at $4000 \mathrm{rpm}$ at room temperature. Finally, the supernatants were collected. The supernatant contains only the simple phenolics other than the non-phenolic contents (the tannins were precipitated along with the PVPP). The total phenol content was measured and expressed as the content of non-tannin phenolics.

\section{Tannins $=$ Total phenols-Non tannin phenols}

\section{In vitro antioxidant assays}

\section{Phosphomolybdenum assay}

The antioxidant activity of samples was evaluated by the green phosphomolybdenum complex formation according to the method [18]. About $40 \mu \mathrm{L}$ aliquots of a sample or ascorbic acid in $1 \mathrm{mmol}$ dimethyl sulphoxide (standard) or distilled water (blank) were added with $1 \mathrm{ml}$ of reagent solution $\left(0.6 \mathrm{M}\right.$ sulphuric acid $\left(\mathrm{H}_{2} \mathrm{SO}_{4}\right)$, $28 \mathrm{mmol}$ sodium phosphate, and $4 \mathrm{mmol}$ ammonium molybdate) in each test tubes. All the test tubes were covered with foil and incubated under a water bath for about $90 \mathrm{~min}$ at $95^{\circ} \mathrm{C}$. Later than, the samples were cooled to room temperature, the absorbance of the mixture was measured at $695 \mathrm{~nm}$ against the reagent blank. The results reported (Total antioxidant capacity) are mean values expressed as mg AAE/g extract (Ascorbic Acid Equivalents per gram extract).

\section{DPPH radical scavenging activity}

The antioxidant activity of the extract was determined in terms of hydrogen donating or radical scavenging ability using the stable radical 2,2-diphenyl-1-picrylhydrazyl (DPPH), according to the method of [19]. Various concentrations of sample extracts were taken and the volume was finalized to $100 \mu \mathrm{l}$ with methanol. About 5 $\mathrm{ml}$ of a $0.1 \mathrm{mmol}$ methanolic solution of DPPH was added to the aliquots of samples and standards (BHA, BHT, Rutin, and Quercetin) and shaken vigorously. The negative control was prepared by adding $100 \mu \mathrm{l}$ of methanol in $5 \mathrm{ml}$ of $0.1 \mathrm{mmol}$ methanol solution DPPH. All the test tubes were incubated at $27^{\circ} \mathrm{C}$ for $20 \mathrm{~min}$. The absorbance was measured at $517 \mathrm{~nm}$ against the blank (methanol). Radical scavenging activity of the samples was expressed as IC50 which is the concentration of the sample required to inhibit $50 \%$ of $\mathrm{DPPH}^{\text {. }}$ concentration.

\section{Nitric oxide scavenging activity}

The Nitric oxide scavenging activity was determined by the method [20], where sodium nitroprusside in aqueous solution at physiological $\mathrm{pH}$, spontaneously generates nitric oxide, which interacts with oxygen to produce nitrite ions that can be estimated using Greiss reagent. Nitric oxide scavengers compete with oxygen leads to a reduction in the production of nitrite ions. For the experiment, sodium nitroprusside $(10 \mathrm{mmol})$ in phosphate-buffered saline (0.2 M, pH-7.4) was mixed with various concentrations of sample solution of various extracts or BHT and Rutin (standard) and incubated at room temperature for $150 \mathrm{~min}$. The same reaction mixture without the sample was used as a negative control. After incubation, $0.5 \mathrm{ml}$ of Griess reagent (1\% sulfanilamide, $2 \% \mathrm{H}_{3} \mathrm{PO}_{4}$ and $0.1 \% \mathrm{~N}$-(1-naphthyl), ethylenediamine dihydrochloride) were added. The absorbance of the chromophore formed was read at 546 $\mathrm{nm}$ against the blank (phosphate buffer). The scavenging activity (\%) was calculated as:

\section{Radical scavenging activity $(\%)=[(\mathrm{A} 0-\mathrm{A} 1) / \mathrm{A} 0] \mathrm{X} 100$}

Where $\mathrm{A} 0$ is the absorbance of the control and $\mathrm{A} 1$ is the absorbance of sample extract/standard.

\section{In vitro anti-inflammatory activity \\ RBC membrane stabilization method}

The membrane-stabilizing activity assay was carried out with minor changes as previously described [21, 22]. The collected blood sample was mixed with an equal volume of sterilized Alsever solution ( $2 \%$ dextrose, $0.8 \%$ sodium citrate, $0.05 \%$ citric acid and $0.42 \%$ sodium chloride in water). The whole mixture was centrifuged at $3000 \mathrm{rpm}$ and the packed cells were washed up with isosaline $(0.85 \%, \mathrm{pH} 7.2)$. The assay mixture with the sample extract $(0.5 \mathrm{ml} ; 50-1000 \mu \mathrm{g} / \mathrm{ml}) /$ Diclofenac-sodium standard drug $(0.5 \mathrm{ml}$; $50,100,200 \mu \mathrm{g} / \mathrm{ml}), 1 \mathrm{ml}$ phosphate buffer $(0.15 \mathrm{M}, \mathrm{pH} 7.4), 2 \mathrm{ml}$ of hyposaline $(0.36 \%)$ and $0.5 \mathrm{ml}$ of HRBC suspension was added and incubated at $37^{\circ} \mathrm{C}$ for $30 \mathrm{~min}$ and centrifuged for $20 \mathrm{~min}$ at 3000 $\mathrm{rpm}$. The total hemoglobin content in the suspension was estimated using a spectrophotometer at $560 \mathrm{~nm}$. The percentage of hemolysis produced in the presence of distilled water was taken as $100 \%$. The RBC membrane stabilization or protection was calculated using the formula:

$\%$ Stabilization $=100-[(\mathrm{A} 1($ sample $/$ standard $) / \mathrm{A} 0($ control $)] \times 100$, where $\mathrm{A} 0$ was the absorbance of the control reaction and A1was the absorbance in the presence of the sample/standard (Diclofenacsodium). 


\section{Statistical analysis}

The results were expressed as mean $\pm \mathrm{SD} / \mathrm{SEM}$. The data were statistically analyzed using SPSS version 2.0 using one-way ANOVA followed by Duncan's test for antioxidant studies. Mean values were measured statistically significant when $p<0.05, p<0.01$ and $p<0.001$.

\section{RESULTS}

Qualitative phytochemical screening on S. brunonianum plant parts such as stem, root, and the flower was carried out to detect the presence of numerous bioactive compounds, both primary and few classes of secondary metabolites.

Table 1: Result obtained from phytochemical screening of $S$. brunonianum

\begin{tabular}{lllll}
\hline Test & Name of the test & Observation & Results & Stem \\
& & & ++ & Root \\
Phenolics & Ferric chloride test & Dark green color & + & + \\
Tannin & Potassium hydroxide test & Dirty ppt & + & + \\
Glycosides & Borntrager's test & Pink color & + & + \\
Phytosterols & Libermann Burchard's test & An array of color changes & + \\
Fixed oils and fats & Saponification test & Formation of soap & + \\
Gums and mucilage & Absolute alcohol test & White ppt & + & + \\
+
\end{tabular}

$(+)$ : indicates the presence of chemical compound, $(-)$ : indicates of absence of chemical compound. $(+)<(++)<(+++)$ : Based on the intensity of distinguishing color.

Phytochemical screening of the plant parts revealed the presence of flavonoids, tannins, saponins, carbohydrates, and Phytosterols are high in stem compared to root and flower.

\section{Total phenol and tannin contents}

The contents of phenols, tannins and flavonoids varied significantly concerning the solvent extracts used (table 2). The methanolic extract of the stem shows the highest contents of total phenol, flavonoid, and tannin. However, the water extract of the stem expressed a lower level of polyphenols compared to other parts.

\section{In vitro free radicals scavenging activities}

\section{DPPH॰ scavenging activities of $S$. brunonianum}

The DPPH radical scavenging activities of Sarcostemma extracts are shown in (fig. 1). In this assay, synthetic (BHT) and natural antioxidant (rutin) were used as a reference control. Methanol extracts showed superior activities compared to other solvent extracts; methanol extract of $\boldsymbol{S}$. brunonianum stem $\left(\mathrm{IC}_{50}\right.$ : 19.71 $\mu \mathrm{g} / \mathrm{ml})$, root $\left(\mathrm{IC}_{50}: 40.68 \mu \mathrm{g} / \mathrm{ml}\right)$ and water extract of the stem $\left(\mathrm{IC}_{50}\right.$ : $36.48 \mu \mathrm{g} / \mathrm{ml}$ ) showed maximum DPPH radical scavenging activities which are comparable to the standards BHT ( $\mathrm{IC}_{50}: 5.19 \mu \mathrm{g} / \mathrm{ml}$ ), and Rutin ( $\mathrm{IC}_{50}: 6.48 \mu \mathrm{g} / \mathrm{ml}$ ). Overall, the free radical scavenging activity was found to be lower in ethyl acetate extracts.

\section{Total antioxidant capacity}

The total antioxidant capacity (TAC) of the plant extracts was determined using a phosphomolybdate assay (fig. 2). The assay activity is based on the reduction of molybdenum (VI) into molybdenum (V) in the presence of a reducing agent (antioxidant), forming a green phosphomolybdate(V) complex, and evaluated spectrophotometrically at $765 \mathrm{~nm}$. Fig. 2. Among different parts used, the methanol extract of the stem has shown a better antioxidant capacity (834.67 mg AAE/g extract) followed by ethyl acetate. This order of activity from polar aqueous to nonpolar petroleum ether extract is quite normal since the polar solvents have a much stronger ability to dissolve and extract polar phytochemicals. The lower antioxidant capacities of the flower extracts. Root part of methanol extract also showed higher antioxidant capacity (498.67 mg AAE/g extract) as compared to other solvent extracts. Thus, the antioxidant capacity observed from the extracts of $S$. brunonianum can be correlated with its free radical scavenging activity equivalent to that of natural antioxidant ascorbic acid.

\section{Nitric oxide activity}

Nitric oxide (NO) has a significant role in various types of inflammatory processes in the animal body. Scavenging NO activities is detrimental to human health. The scavenging activities of various samples on nitric oxide were analyzed and the percentage of scavenging activities of stem, bark and fruit of $S$. brunonianum are shown in (fig. 3). The Nitric oxide radical scavenging activity of stem, root and flower extracts of the plant showed greater \% of inhibition, especially in methanol extract of the stem $(24.39 \mu \mathrm{g} / \mathrm{ml})$, root extract $(26.48 \mu \mathrm{g} / \mathrm{ml})$ followed by ethyl acetate stem extract $(30.03 \mu \mathrm{g} / \mathrm{ml})$. The scavenging activities of all extracts were comparable with that of Rutin and BHT. The scavenging of nitric oxide assay has shown the relevant inhibitory concentration in the methanolic extract of the bark sample. The result indicates that the sample extracts might contain some compounds which can inhibit nitric oxide and offers scientific evidence for the utilization of the plant in the inflammatory condition.

Table 2: Showing total phenol and tannin contents found in $S$. brunonianum plant parts

\begin{tabular}{llll}
\hline Parts & Solvent extraction & Total phenols (GAE mg/g) & Total tannins (GAE mg/g) \\
\hline Stem & Petroleum ether & $285.9477 \pm 18.53^{\mathrm{c}}$ & $149.7778 \pm 8.49$ \\
& Chloroform & $249.3464 \pm 12.53$ & $230.2222 \pm 2.34^{\mathrm{c}}$ \\
& Ethyl acetate & $290.5229 \pm 16.44^{\mathrm{b}}$ & $291.7778 \pm 4.68^{\mathrm{a}}$ \\
& Methanol & $440.8497 \pm 69.98^{\mathrm{a}}$ & $264.2222 \pm 13.10^{\mathrm{b}}$ \\
\multirow{3}{*}{ Root } & Water & $166.9935 \pm 13.91$ & $148 \pm 33.24$ \\
& Petroleum ether & $144.1176 \pm 18.53$ & $151.7778 \pm 3.28$ \\
& Chloroform & $192.4837 \pm 10.06$ & $161.3333 \pm 1.33$ \\
& Ethyl acetate & $199.6732 \pm 9.86^{\mathrm{c}}$ & $174.4444 \pm 1.38^{\mathrm{c}}$ \\
& Methanol & $365.6863 \pm 7.84^{\mathrm{a}}$ & $281.5556 \pm 4.91^{\mathrm{a}}$ \\
\multirow{3}{*}{ Flower } & Water & $72.87582 \pm 7.92$ & $239.778 \pm 11.08^{\mathrm{b}}$ \\
& Petroleum ether & $34.3137 \pm 8.98$ & $142.8889 \pm 3.90$ \\
& Chloroform & $59.15 \pm 6.3^{\mathrm{c}}$ & $157.7778 \pm 2.77^{\mathrm{c}}$ \\
& Ethyl acetate & $171.5686 \pm 15.31^{\mathrm{a}}$ & $170.8889 \pm 4.72^{\mathrm{b}}$ \\
& Methanol & $152.6144 \pm 10.8^{\mathrm{b}}$ & $180.4444 \pm 4.43^{\mathrm{a}}$ \\
& Water & $32.35294 \pm 5.89$ & $141.7778 \pm 2.03$ \\
\hline
\end{tabular}

GAE-Gallic Acid Equivalents; Values are mean of triplicate determination (n=3) \pm standard deviation (SE); statistically significant at $p<0.05$ where $\mathrm{a}>\mathrm{b}>\mathrm{c}$ in each column. 


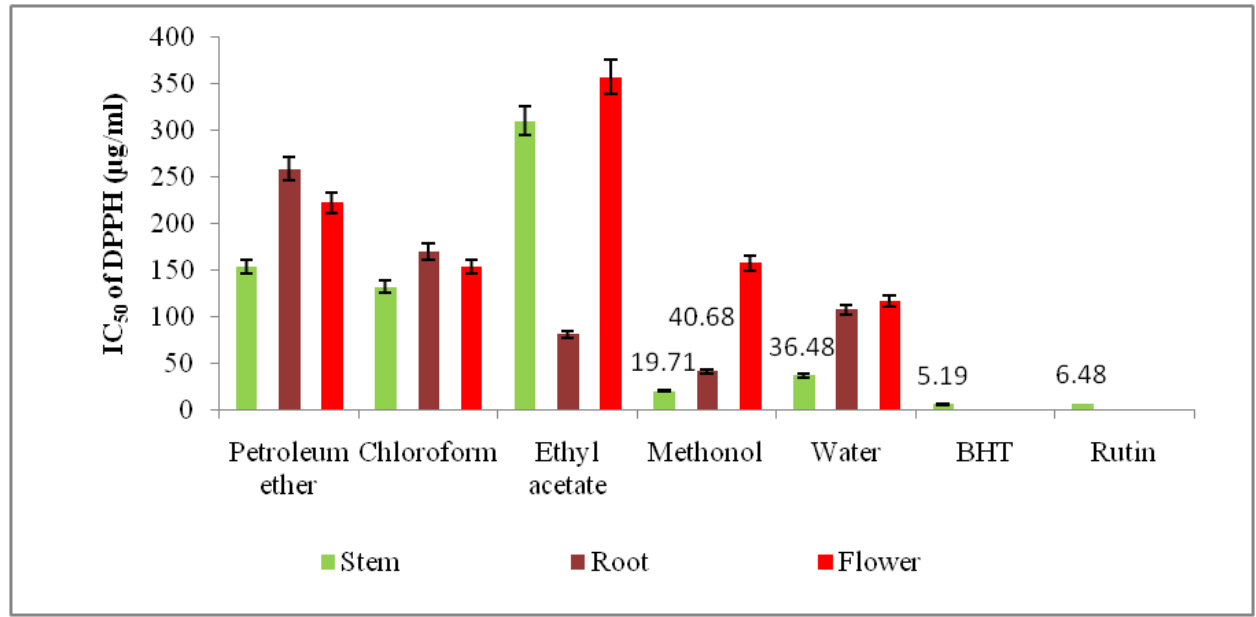

Fig. 1: DPPH॰scavenging activity

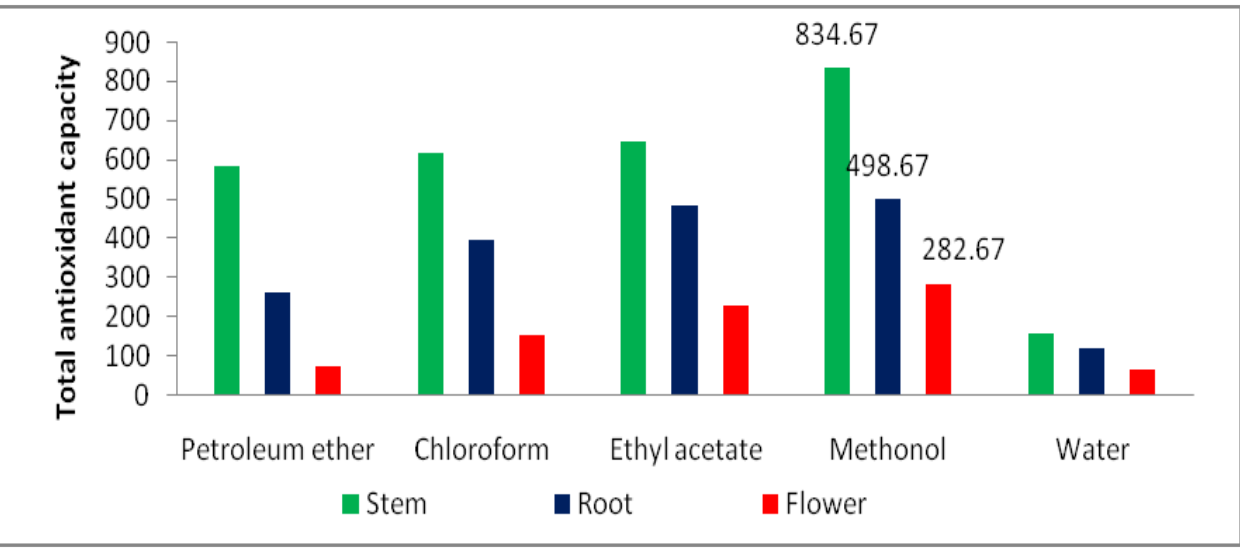

Fig. 2: Total antioxidant capacity

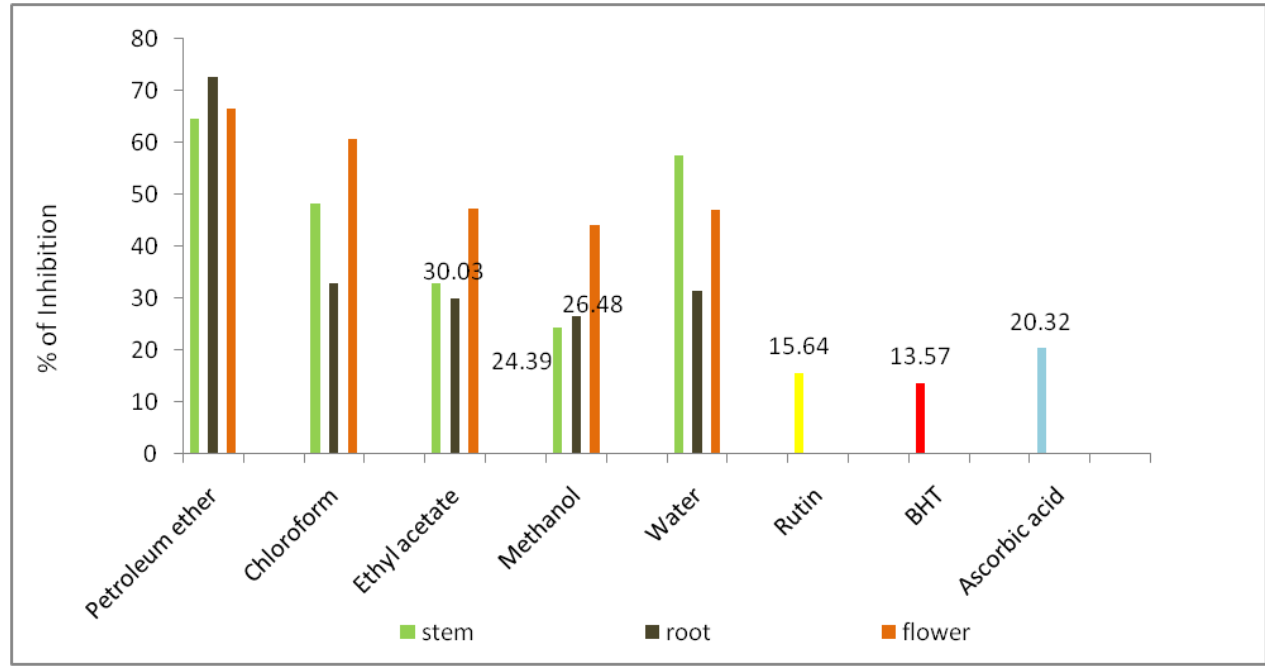

Fig. 3: Nitric oxide activity

\section{In vitro anti-inflammatory activity}

The methanol and ethyl acetate extract of the stem of Sarcostemma brunonianum were studied for in vitro anti-inflammatory activity by the RBC membrane stabilization method. Fig. 4 five different kinds of extract were used among which stem methanol (55.56\%) and flower (53.62\%) have shown higher \% of inhibition of RBC in a hypotonic solution. 


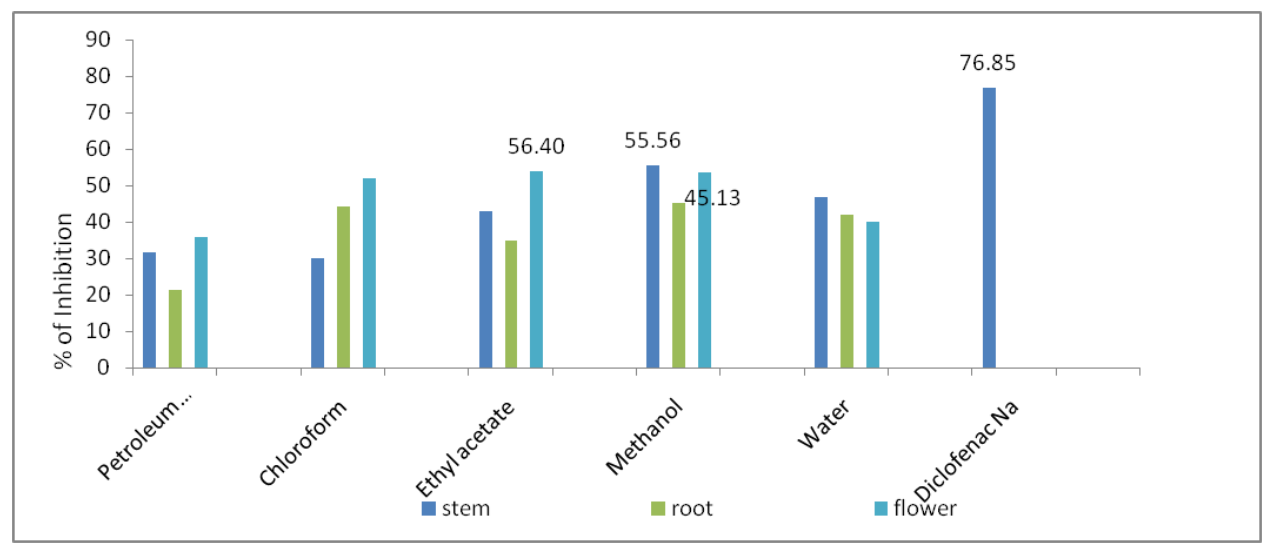

Fig. 4: Anti-inflammatory activity

All the results were compared with standard Diclofenac Sodium, which showed $76.85 \%$ protection. This activity may be due to the presence of phytochemical constituents present in the sample extract.

\section{DISCUSSION}

The study provides a piece of strong evidence for the use of Sarcostemma in folkloric treatment as an anti-inflammatory agent. Therefore, the plant could be suggested as a natural source of membrane stabilizers and was capable of providing an alternative remedy for the management and treatment of inflammatory-related disorders and diseases [5]. For phenolic composition, results demonstrated that methanol was a better solvent in extracting polyphenols. Therefore, the polarity of the solvent will play an important role in increasing the solubility of phenols [23]. Then, a variation of phenol accumulation between plant parts should be related to their specific cells and tissues. The high presence of phenols in plant parts is attributed to the phenological organ growth, transport involved in polyphenols distribution, the interaction between plant parts and biosynthesis processes [24]. Observed antioxidants and the presence of the active phytochemicals in attributed to a good source of a pharmaceutical drug. Thus, the plant can be used as a source for antioxidant components as well as an alternative drug against Nonsteroidal antiinflammatory drugs (NSAIDs). Discovering novel, effective and safe anti-inflammatory agents has remained a major thrust area in the field of developing alternatives to NSAIDs.

The test for the analysis of phytochemical compounds put forth a way to determine therapeutic drugs progressively. Preliminary phytochemical analysis made for the stem, root, and flower of $S$. brunonianum revealed the presence of alkaloids, saponins, phenolics, tannins, flavonoids, glycosides, phytosterols, and other bioactive compounds, Till date, phytochemical investigation and other studies on $S$. brunonianum has not yet been studied completely. Hence, the present study was focused to determine phytochemicals, to evaluate the antioxidant potential of plant extracts and It can be concluded that $S$. brunonianum is a therapeutically potential herb that can be attributed to its phytoconstituents and justifies its use in the folklore system of medicine. Besides, ethyl acetate and methanolic extracts also showed anti-inflammatory activity, which was quite comparable to the one observed for diclofenac at $10 \mathrm{mg} / \mathrm{kg}$ and the results were found statistically significant.

\section{CONCLUSION}

Investigation on phytochemicals has indicated the presence of phenols, tannins, glycosides, gums and mucilages. This study has also shown the presence of phenolic compounds in S. brunonianum suggests that the antioxidant activity may be due to the polyphenol contents. Such kind of effective natural antioxidants can replace the synthetic ones that can be used in foods and cosmetics. Thus, the valuable source of $S$. brunonianum could be employed in varied medicinal preparations to combat inflammatory diseases associated with oxidative stress and related disorders. The obtained results demonstrated that methanol was the most effective solvent to extract phytochemical compounds compared to petroleum ether, chloroform, ethyl acetate and aqueous. In conclusion, these results reveal that $S$. brunonianum has significant antioxidant and antiinflammatory properties. An overall positive correlation between anti-inflammatory and antioxidant activity was observed.

\section{ACKNOWLEDGMENT}

We are highly thankful to Phytochemistry Lab, Dept of Botany, Bharathiar University, DST-FIST, PURSE and SERB for providing all kind of support during this research.

\section{FUNDING}

Nil

\section{AUTHORS CONTRIBUTIONS}

All the authors have contributed equally.

\section{CONFLICTS OF INTERESTS}

The authors strongly declare that there is no conflict of interest.

\section{REFERENCES}

1. Sarvalingam A, Dhaarani V, Pavithra C, Sharmila S, Rajendran A. Inventory and ethnomedicinal plants used by rural people of Eastern Ghats of Tamil Nadu, India. J Ecobiotechnol 2017;9:512.

2. Amala Divya S, Thamarai Kani V, Vijaya Lakshmi. A report on some lactiferous species of maruthamalai hills of the Southern Western ghats of coimbatore district, India. Res Rev: J Ecol 2018;7:1-7.

3. Gritto MJ, Nandagopalan V, Doss A. Ethnobotanical study on the traditional healers in pachamalai hills of Eastern Ghats, Tamil Nadu, South India. J Med Plants Stud 2015;3:80-5.

4. Pandey S, Shukla A, Pandey S, Pandey A. Morphology, chemical composition and therapeutic potential of somlata (sarcostemma acidum wight. and arn.). Pharma Sci Monitor 2017;8:54-60

5. Shailesh G, Seema K, Dwivedi S. In vitro anti-inflammatory activity of sarcostemma acidum wight and Arn. Indian herb by Human red blood cell membrane stabilization method. Int $\mathrm{J}$ 2011;2:184-8.

6. Abdel Kader MS, Hazazi AM, Elmakki OA, Alqasoumi SI. A survey on traditional plants used in Al Khobah village. Saudi Pharm J 2018;26:817-21.

7. Sekar K, Thangaraj S, Babu SS, Harisaranraj R, Suresh K. Phytochemical constituent and antioxidant activity of extract from the leaves of ocimum basilicum. J Phytol 2009. https://doi.org/10.1155/2019/2628747

8. Gangwar M, Gautam MK, Sharma AK, Tripathi YB, Goel RK, Nath G. Antioxidant capacity and radical scavenging effect of 
polyphenol-rich Mallotus philippenensis fruit extract on human erythrocytes: an in vitro study. Sci World J 2014. DOI:10.1155/2014/279451.

9. Tawaha K, Alali FQ, Gharaibeh M, Mohammad M, El-Elimat T. Antioxidant activity and total phenolic content of selected Jordanian plant species. Food Chem 2007;104:1372-8.

10. Melinda KP, Rathinam X, Marimuthu K, Diwakar A, Ramanathan $\mathrm{S}$, Kathiresan S, et al. A comparative study on the antioxidant activity of methanolic leaf extracts of Ficus religiosa L, Chromolaena odorata (L.) king and rabinson, Cynodon dactylon (L.) pers. and tridax procumbens L. Asian Pacific J Trop Med 2010;3:348-50.

11. Tharun G, Pindi PK. Evaluation of antioxidant potential and antimicrobial activity of successive extracts of Pimpinella tirupatiensis. J Pharm Res 2013;7:817-22.

12. Evans WC. Trease and evans pharmacology. Harcourt Brace Company Asia. Pvt. Ltd. Singapore; 1997.

13. Herborne JB. A guide to modern techniques of plant analysis. Phytochemical Methods 1973. p. 5-11.

14. Odebiyi 00, Sofowora EA. Phytochemical screening of Nigerian medicinal plants II. Lloydia 1978;41:234.

15. Raaman N. Phytochemical techniques new India publishing agency. Chapter Six; 2006. p. 40-67.

16. Siddhuraju P, Manian S. The antioxidant activity and free radical-scavenging capacity of dietary phenolic extracts from horse gram (Macrotyloma uniflorum (Lam.) Verdc.) seeds. Food Chem 2007;105:950-8.
17. Siddhuraju P, Becker K. Studies on antioxidant activities of mucuna seed (Mucuna pruriens var utilis) extract and various non-protein amino/imino acids through in vitro models. J Sci Food Agric 2003;83:1517-24.

18. Prieto P, Pineda M, Aguilar M. Spectrophotometric quantitation of antioxidant capacity through the formation of a phosphomolybdenum complex: specific application to the determination of vitamin E. Anal Biochem 1999;269:337-41.

19. Blois MS. Antioxidant determinations by the use of a stable free radical. Nature 1958;181:1199-200.

20. Rao MNA. Nitric oxide scavenging by curcuminoids. J Pharm Pharmacol 1997;49:105-7.

21. Mizushima Y, Kobayashi M. Interaction of anti-inflammatory drugs with serum proteins, especially with some biologically active proteins. J Pharm Pharmacol 1968;20:169-73.

22. Oyedapo O0, Akinpelu BA, Orefuwa SO. Anti-inflammatory effect of theobroma cacao, root extract. J Trop Med Plants 2004;5:161-6.

23. Roby MHH, Sarhan MA, Selim KAH, Khalel KI. Evaluation of antioxidant activity, total phenols and phenolic compounds in thyme (Thymus vulgaris L.), sage (Salvia officinalis L.), and marjoram (Origanum majorana L.) extracts. Industrial Crops Products 2013;43:827-31.

24. Hudaib M, Speroni E, Di Pietra AM, Cavrini V. GC/MS evaluation of thyme (Thymus vulgaris L.) oil composition and variations during the vegetative cycle. J Pharm Biomed Anal 2002;29:691700 . 